\title{
The Effectiveness of Parental Education via Smartphone Application on Number of Utterances and Initiation Ratio
}

\author{
Wonjeong Park, Dongsun Yim \\ Department of Communication Disorders, Ewha Womans University, Seoul, Korea
}

Correspondence: Dongsun Yim, PhD Department of Communication Disorders, Ewha Womans University, 52 Ewhayeodae-gil, Seodamun-gu, Seoul 03760, Korea

Tel: $+82-2-3277-6720$

Fax: +82-2-3277-2122

E-mail: sunyim@ewha.ac.kr

Received: October 5, 2015

Revised: November 6, 2015

Accepted: November 14, 2015

This work was supported by the Korean government (Ministry of Science, ICT and Future Planning) in 2013 (NRF-2013R1A2A2A03068010).

\begin{abstract}
Objectives: Children with language delay have low competence in lexical, grammatical knowledge and pragmatic skills. The problems they have can affect their later academic performance and peer relationships. Therefore early intervention is highly recommended. One of the effective methods for early intervention is parental education. However, parents have difficulty in generalizing the strategies they have learned. Thus, the purpose of this study was to explore the effectiveness of using a smartphone application as a tool for increasing the effectiveness of parental education. Methods: Eight mothers and their children with language delay between 2 and 3 years old participated in this study. As a pretest researchers collected spontaneous language samples. After the pre-test, 6 sessions of parental education were conducted. During the parental education, four parents were asked to use the smartphone application during parent-child interaction. But, the rest of the parents were asked to keep a log of the duration of interaction instead of using the smartphone application. After the end of all sessions, a post-test was conducted in the same method as the pre-test. Each spontaneous speech sample was collected and analyzed for the number of utterances and initiation ratio. Results: The children in the experimental group, who used the smartphone application during parental education showed higher intervention effects than the control group. Conclusion: Parental education can modify parent-child interaction style in positive and effective ways. Additionally, smartphone applications can feasibly increase the effect of parental education.
\end{abstract}

Keywords: Children with language delay, Parental education, Smartphone application, Initiation ratio, Number of utterances
언어 발달은 아동의 다양한 발달 과정 중 일부에 불과하지만, 아 동을 둘러싼 주변 환경에 대해 많은 정보를 제공하기 때문에 인지 적 성숙에 중요한 역할을 한다(Owens, 1996). 또한 아동이 건강한 사회구성원으로서 성장하는 것에도 필수적인 과정이다(Hegde, 1995). 때문에 언어발달지연 아동에게서 나타나는 저하된 언어 능 력은 사회적 존재로서의 아동의 성장을 저해하는 요소가 된다.

아동의 언어발달지연은 일반적으로 만 2 세 이후, 또래와의 표현 어휘 차이를 통해 드러나며(Paul, Hernandez, Taylor, \& Johnson, 1996; Scarborough \& Dobrich, 1990), 어휘 다양도에서도 정상 발 달 아동과의 차이를 보인다(Klee, 1992; Lee \& Kim, 1999). 구문적
측면에서는 단어 조합, 평균발화길이 등의 문제가 나타난다(Rescorla, Roberts, \& Dahlsgaard, 1997; Whitehurst \& Fischel, 1994). 단어 조합은 정상 발달 아동에게서 일반적으로 만 2 세 무렵에 가 능해지지만, 언어발달지연 아동의 경우 단어 조합이 불가능하거나 거의 나타나지 않게 된다(Fischel, Whitehurst, Caulfield, \& DeBaryshe, 1989; Tsybina \& Eriks-Brophy, 2007). 아동의 생활연령을 반영하는 지표로서 임상에서 아동의 언어발달 수준을 평가하는 것에 사용되는 평균발화길이에서도(Brown, 1973; Kim, 1997) 언어 발달지연 아동은 정상 발달 아동에 비해 유의미하게 짧은 발화를 산출하는 것으로 나타났다(Lee \& Kim, 1999). 
언어발달지연 아동은 어휘, 구문적 측면과 같이 언어 구조적 측 면을 보여주는 언어 발달 지표 전반에서 저하된 양상을 보일 뿐 아 니라 의사소통 기능 및 상호작용 기술에서도 또래 일반 아동에 비 해 다른 경향을 보인다. 성인과의 상호작용 과정에서 언어 습득에 중요한 기여를 하는 공동 주목하기, 성인과의 사회적 상호작용을 시작하거나 지속하는 데 필요한 기술에서도 차이를 내며(Cho \& Lee, 2010), 부모와의 상호작용에서 또래 아동에 비해 적은 빈도의 대화 개시를 보이고, 대화를 유지하는 것에서도 어려움을 나타낸 다고 보고되었다(Cunningham, Siegel, Van der Spuy, Clark, \& Bow, 1985; Paul \& Shiffer, 1991). 또한 언어발달지연 아동은 자발 화상황에서 주어진 시간 내에 산출하는 발화수 및 대화차례 개시, 반응, 대화차례 주고받기 전반에서도 정상 발달 아동에 비해 지연 된 경향을 보인다(Yim, Park, Cheon, Lee, \& Lee, 2015).

이와 같은 언어발달지연 아동의 언어 문제는 성장 이후에도 아동 의 언어 능력 전반에 영향을 미칠 수 있으며(Goffman \& Leonard, 2000; Paul, 1991; Rescorla, 2005, 2009; Rice, Taylor, \& Zubrick, 2008), 정상 범위의 어휘 수준을 갖게 되어도 여전히 또래 평균에 비해 저하된 양상을 보이거나(Paul, 1991), 학령기 어휘력, 문법, 언 어적 기억, 읽기 이해력 등 전반적 언어 기술의 취약성을 통해 나타 나기도 한다(Rescorla, 2005). 특히 화용 및 상호작용 기술 측면에서 의 문제는 학령기 이후 아동의 또래 관계 및 학업에 영향을 줄 가능 성이 있는 것으로 알려졌다(Owens, 2004). 따라서 적절한 시기에 아동에게 언어를 중재하는 것은 상당히 중요하다(Kuhl, Conboy, Padden, Nelson, \& Pruitt, 2005).

언어발달지연 아동 조기중재 목표는 언어 수행력을 정상 범위의 또래 수준에 이르도록 하는 것이다. 이에 효과적인 간접 중재 전략 으로서 부모교육이 실시된다. 부모를 통하여 이루어지는 언어발달 지연 아동의 간접 중재는 아동에게 가장 자연스러운 대화상대자, 그리고 아동에게 가장 자연스러운 물리적 환경을 통하여 이루어지 기 때문에 아동의 상호작용 기술 및 언어 발달을 촉진하는 데 기여 한다(Tsybina \& Eriks-Brophy, 2007). 대표적인 언어발달지연 아동 의 부모교육 프로그램으로 Hanen Center의 It Takes Two To Talk 가 있다. It Takes Two To Talk는 아동이 일상에서 의미 있는 대화 상대자와의 의사소통을 통해 언어를 습득한다는 가정을 바탕으로 하여(Pepper \& Weitzman, 2004), 의사소통 상대자로서 부모가 아 동의 언어 발달을 촉진시키기 위하여 사용할 수 있는 전략을 교수 하는 방식으로 부모교육이 실시된다. It Takes Two To Talk 프로그 램을 통한 부모교육은 언어발달지연 아동의 공동 주목하기, 눈 맞 추기, 발성과 같은 의사소통 행동을 증가시키고(Kim \& Lee, 2007), 단어 조합과 형태소 습득에 긍정적인 영향을 줄수 있다(Girolamet- to, Pearce, \& Weitzman, 1996) 이는 단순히 언어 발달에만 지체를 보이는 일차적 언어발달지연 아동뿐만 아니라 다운증후군, 뇌성마 비와 같은 이차적 언어발달지연 아동에게도 적용되어 상호작용 능 력 향상에 영향을 줄 수 있다(Girolametto, Weitzman, \& ClementsBaartman, 1998; Jung, Sim, \& Yim, 2012; Pennington, 2009).

그러나 부모교육의 난점은 학습한 전략이나 중재 내용을 가정에 서 직접 적용하는 것이 어렵다는 것이다. 때문에 소그룹 내 시연 활 동, 전문가의 비디오 피드백의 활용, 발화 피드백을 위한 기기 사용 과 같은 다양한 전략이 사용된다(Pepper \& Weitzman, 2004; Suskind et al., 2013). 이 중 발화 분석 기기인 LENA (Language Environment Analysis)를 통해 피드백을 제공함으로써 부모교육의 효 과를 높이는 전략은 전문가의 도움 없이 부모가 손쉽게 가정에서 실천할 수 있기 때문에 활용도가 높게 평가된다(Suskind et al., 2013). 하지만 LENA는 가격 면에서도 비효율적임은 물론, 영어권 국가를 대상으로 개발되어 국내에서의 사용에 어려움이 따를 수 있다. 이 에 따라 높은 스마트폰 보급률을 반영하여 최근, 부모 및 아동의 발 화를 분석하고 피드백을 제공하는 어플리케이션이 국내에서 개발 되었다(Hwang et al., 2014). 스마트폰 어플리케이션을 통한 기기적 접근은 누구나 쉽게 활용할 수 있다는 장점이 있으나 임상 적용 가 능성에 대한 추가적 연구 없이 활용되기에는 어려움이 따른다. 특 히 언어치료 현장에서 부모교육 중재의 보조 수단으로서의 효과성 및 적용가능성을 알아보는 연구는 전무한 실정이기에 이에 대한 연구가 이루어져야 할 것이다.

따라서 본 연구는 언어발달지체 아동의 부모를 대상으로 한 부 모교육 중재가 아동과 부모의 발화 및 상호작용 기술에 영향을 미 치는지, 그리고 부모교육의 효과를 가정에 적용하는 것에 도움을 주는 수단으로서 발화분석 어플리케이션의 가능성에 대해 탐색하 는 것을 목적으로 하였다. 구체적인 연구 문제는 다음과 같다.

1) 부모교육 중재 기간 동안 발화분석 어플리케이션을 사용한 부 모 집단과 사용하지 않은 집단 간에 부모교육 중재 효과(발화 수, 대화차례 개시 비율)에서 차이가 나타나는가?

2) 부모교육 중재 기간 동안 발화분석 어플리케이션을 사용한 아동 집단과 사용하지 않은 집단 간에 부모교육 중재 효과(발화 수, 대화차례 개시 비율)에서 차이가 나타나는가?

\section{연구 방법}

\section{연구대상}

본 연구는 언어발달이 지연된 아동과 그 부모를 대상으로 하였 으며, 아동의 경우 다음과 같은 기준에 따라 선정되었다. 먼저 (1) 생 
Table 1. Participants' characteristics

\begin{tabular}{lccc}
\hline Characteristic & $\begin{array}{c}\text { Experimental group } \\
(\mathrm{N}=4)\end{array}$ & $\begin{array}{c}\text { Control group } \\
(\mathrm{N}=4)\end{array}$ & $F$ \\
\hline Age & & & \\
$\quad$ Parents (yr) & $34.00(3.46)$ & $34.00(2.58)$ & .000 \\
$\quad$ Children (mo) & $30.25(4.11)$ & $29.00(1.63)$ & .319 \\
$\quad$ Range & $25-34$ & $27-31$ & \\
Children's vocabulary test $^{\mathrm{a}}$ & $20.50(25.94)$ & $22.75(19.12)$ & .087 \\
\hline
\end{tabular}

Values are presented as mean (SD).

aKorean MacArthur-Bates Communicative Development Inventories (Pae \& Kwak, 2011).

활연령이 만 2-3세에 해당하는 남녀 아동으로서, (2) 한국판 맥아 더-베이츠 의사소통발달 평가 기록지(K M-B CDI; Pae \& Kwak, 2011) 결과 $10 \%$ ile 미만에 해당하고, (3) 발화를 통한 의사 표현이 가능하며, (4) 인지 및 청력기관에 문제가 없는 아동을 대상으로 하 였다. 부모의 경우 (1) 해당 아동의 주 양육자이며, (2) 고등학교 졸 업 이상의 학력을 지니고, (3) 인지 및 청력기관에 문제가 없으며 (4) 이전에 부모-아동 상호작용 촉진과 관련한 부모교육을 받은 경험 이 없는 자를 기준으로 하여 대상자를 선정하였다. 이와 같은 대상 자 기준에 따라 선발된 아동과 부모는 총 8 쌍이며, 발화분석 어플 리케이션을 통해 제공되는 피드백이 부모교육의 효과를 높여주는 지 알아보기 위해 대상자를 생활연령을 일치시킨 두 집단으로 나 누어 실험집단과 통제집단으로 구분하였다. 두 집단의 언어 검사 결과 및 생활연령에는 통계적으로 유의한 차이가 없었다. 각 집단 아동 및 부모에 관한 대상자 정보는 Table 1에 제시되어 있다. 또한, 중재 이전 25 분간의 부모-아동 상호작용을 통하여 실시된 자발화 수집 및 분석 결과, 각각의 종속변수에서 두 집단 간 차이는 모두 통계적으로 유의하지 않았다.

\section{연구도구}

본 연구에서 사용된 발화분석 어플리케이션은 아동 및 성인의 발화 분석을 목적으로 이화여자대학교 언어병리학과와 한국과학 기술원(KAIST) 전산학과의 공동 연구를 통해 개발되었으며 2015 년 현재 활용가능성 및 정확도를 높여 임상에 적용하기 위한 연구 가 진행 중에 있다. 발화 분석 어플리케이션의 분석 항목은 총 2 가 지로 발화수, 대화차례 개시 횟수이다.

발화분석 어플리케이션은 상호작용 동안 부모와 아동의 발화 수와 개시 정도에 관한 시각적 피드백을 제공한다. 상호작용이 끝 난 이후 어플리케이션을 종료하면 그 결과를 분석 항목(발화수, 대 화차례 개시 횟수)에 따라 제시한다. 또한 기존 연구(Yim et al., 2015) 에 기초하여 또래 아동과 비교한 해당 아동의 발화 수, 대화차례 개
시 횟수 비교 그래프를 보여주게 된다. 따라서 부모는 아동과의 상 호작용과 동시에, 그리고 상호작용이 끝난 이후에 이에 관한 피드 백을 받을 수 있다.

\section{연구절차}

사전 검사를 위해 연구 대상 아동의 가정에 방문하거나 자발화 검사가 가능한 장소를 섭외하여 기초선 측정을 위한 자발화 수집 을 실시하였다. 자발화 수집은 부모와 아동의 놀이 상황을 30 분간 관찰함으로써 이루어졌다. 부모와 아동의 놀이를 위하여 제공된 장난감은 스티커 붙이기, 의사놀이, 소꿉놀이이며 각각의 놀이를 약 10 분 정도 사용하여 놀이를 진행토록 하였다. 놀이과정에서 일 어나는 부모와 아동의 상호작용은 영상 녹화와 동시에 음성 녹음 이함께 이루어졌다.

사전검사 종료 후 6 회기에 걸친 부모교육이 실시되었다. 부모교 육은 1 회기에 1 시간 정도 진행되었으며 Hanen Center의 It Takes Two To Talk (Pepper \& Weitzman, 2004)의 내용을 토대로 하여 언 어발달지연 아동의 부모가 상호작용을 촉진할 수 있는 주요 전략 을 중심으로 프로그램을 구성하였다. It Takes Two To Talk의 전략 들은 아동이 자발적으로 의사소통에 참여토록 하고, 성인과의 대 화에 참여할 수 있도록 함으로써 부모와의 상호작용을 돕는다. 이 러한 과정에서 아동에게 언어에 대한 모델링을 제시하고, 아동의 말을 확장해주는 방식을 통해 아동의 언어 발달을 촉진한다(Pepper \& Weitzman, 2004). 부모교육 실시는 Hanen Center를 통하여 It Takes Two To Talk 워크숍을 이수하여 프로그램 수행을 위한 자 격증을 취득한 전문가 1 인에 의해 이루어졌다. 부모교육의 구체적 인 내용은 Appendix 1 에 제시되어 있다.

부모교육의 첫 회기가 끝난 이후, 실험집단의 부모에게는 발화 분석을 통해 피드백을 제공할 수 있는 어플리케이션(삼성 Galaxy Note4에 설치)이 제공되었다. 더불어, 약 15 분에 걸쳐 발화분석 어 플리케이션의 사용 방법 및 결과 해석 방법을 추가적으로 교육하 였다. 즉, 어플리케이션을 통해 발화를 측정하는 방법, 그리고 어플 리케이션의 각 측정 항목이 의미하는 바와 결과치를 해석하는 방 법에 대해 설명하였다. 6 회기의 부모교육이 이루어지는 동안 실험 집단의 부모는 학습한 전략을 아동과의 상호작용에 적용함과 동시 에, 어플리케이션을 사용함으로써 부모 자신과 아동의 발화 수 및 상호작용 기술에 관한 실시간 피드백 및 분석 결과를 받도록 하였 다. 연구자는 부모에게 하루 10-15분 정도 매일 발화분석 어플리케 이션을 사용하도록 하였고 사용 내역은 이메일을 통해 연구자에게 전송되었다. 발화분석 어플리케이션을 사용하지 않는 통제집단의 부모에게도 하루 10-15분 정도 부모교육에서 학습한 전략을 적용 
하고 이에 대한 일지를 적도록 하였다. 통제집단 부모에게 제공된 상호작용 전략 일지는 연구자가 매주 부모교육이 이루어지는 시간 에 제공되었으며, 지난 시간에 학습했던 상호작용 전략을 가정에서 아동과의 상호작용에 적용해보고 전략 사용에 대한 자가 점검 및 소감을 적도록 하였다. 통제집단 부모의 상호작용 일지 작성은 실 험집단과 마찬가지로 사후 검사 전까지 이루어졌다. 일원배치분산 분석을 통해 두 집단의 1 일 평균 상호작용 촉진 전략 사용 시간 차 이를 확인해 본 결과 집단 간 전략 사용 시간에는 통계적으로 유의 한차이가 나타나지 않았다.

부모교육 중재 및 상호작용 전략 사용이 모두 종료된 이후 사후 검사가 실시되었다. 사후 검사는 사전 검사와 동일한 방식으로 이 루어졌다.

\section{자료분석 및 통계적 처리}

사전·사후 자료 수집 결과의 분석은 언어병리학과 석사과정 수 료생 1 인에 의해 이루어졌다. 약 30 분에 걸친 녹음 및 영상 파일을 각각 25 분으로 편집하여 시간을 통제한 후 자발화 분석을 실시하 였다. 자발화 샘플은 사전 및 사후 평가가 이루어진 뒤 1 주일 이내 에 모두 전사 및 분석되었다.

본 연구에서 발화 수는 Lee와 $\operatorname{Kim}$ (2001)의 정의를 따랐으며, 자 발화 수집이 이루어진 25 분 내에 발생된 전체 빈도수로 분석되었 다. 대화차례 개시 비율은 Lee와 Lee (2013)의 기준에 따라 분석되 었으며, 총 발화 수 대비 일어난 빈도수를 백분율화함으로써 산출 하였다. 각각의 자발화 분석 항목에 대한 정의는 Appendix 2에 제 시되어 있다.

본 연구에서 수집된 자료는 IBM SPSS Statistics ver. 19를 사용하 여 분석되었다. 부모교육 중재 과정에서 발화분석 어플리케이션의 사용 여부가 부모와 아동의 발화 수, 대화차례 개시 비율에 영향을 주었는지 알아보기 위해 샤피로-윌크 정규성 검정(Shapiro-Wilk normality test)을 실시한 이후 이원혼합분산분석(two-way mixed ANOVA)을 사용하였다.

\section{신뢰도}

부모와 아동의 발화 수, 대화차례 개시 비율에 대한 검사자 내 신 뢰도를 분석하기 위하여 연구자는 부모와 아동의 전체 데이터 중 $20 \%$ 에 해당하는 자료를 무작위로 선택하여 이에 대한 재분석을 실시하였다. 이에 따른 일치도 분석 결과, 부모 발화 수 $98.67 \%$, 대 화차례 개시 비율 $95.23 \%$ 로 나타났으며, 아동 데이터 분석 결과는 발화수 $94.05 \%$, 대화차례 개시 비율 $92.66 \%$ 로 나타났다.

\section{중재 충실도}

부모교육 프로그램에 대한 대상 부모와 연구자의 중재 충실도를 확인하기 위하여 중재 충실도 체크리스트를 실시하였다. 부모용 중 재 충실도 체크리스트는 총 12 개 문항으로, 중재 계획, 중재 실행, 중재 평가의 세 항목으로 나누어 구성되었다. 먼저 중재 계획에서 는 부모교육에 관한 사전 정보 및 출석률에 대해 점검하였으며, 중 재 실행에서는 각 수업 내용에 대한 이해와 참여 태도, 중재 평가에 서는 일반화에 관한 세부 문항이 포함되었다. 연구자용 중재 충실 도 체크리스트는 총 12 문항으로 부모용 중재 충실도 체크리스트와 마찬가지로 중재 계획, 중재 실행, 중재 평가 크게 세 항목으로 구분 되어 있다. 중재 계획에는 일정과 내용 구성, 중재 실행에는 각 수업 내용별 설명 및 자료 제시, 중재 평가에는 중재 일반화에 관한 세부 문항으로 구성되었다. 중재 충실도 점수는 총점 12점에 대한 산출 점수를 백분율화하여 산출하였다. 먼저, 부모용 중재 충실도 측정 결과 중재 계획 평균 85 점, 중재 실행 평균 81.67점, 중재 평가 평균 95점으로 산출되었다. 또한 연구자의 중재 충실도 측정 결과는 중 재 계획, 실행 및 평가 평균 모두 100 점으로 나타났다.

\section{연구 결과}

\section{중재에 따른 집단별 부모의 발화 수 및 대화차례 개시 비율 비교}

발화분석 어플리케이션 사용 여부에 따른 부모의 부모교육 중 재 효과 차이에 대해 알아보기 위한 통계적 분석을 통하여 집단 간 부모 발화 수를 비교한 결과, 집단 간 효과 검정 결과는 유의하지 않았으나 $\left(F_{(1,6)}=.156, p>.05\right)$, 사전과 사후 평가 간 주효과는 통계 적으로 유의한 것으로 나타났다 $\left(F_{(1,6)}=25.630, p<.05\right)$. 또한 사전. 사후 평가와 어플리케이션 사용 여부 간에는 상호작용 효과가 유 의하지 않은 것으로 나타났다 $\left(F_{(1,6)}=.496, p>.05\right)$. 실험집단과 통제 집단 부모의 발화 수에 대한 기술통계량 및 통계 분석 결과는 Table 2, Figure 1 에 제시되어 있다.

두 부모 집단의 대화차례 개시 비율은 집단 간 주효과 $\left(F_{(1,6)}=\right.$

Table 2. Results from the pre-test and post-test comparison for the number of utterances by parents' subgroup

\begin{tabular}{lccc}
\hline & $\begin{array}{c}\text { Experimental group } \\
(\mathrm{N}=4)\end{array}$ & $\begin{array}{c}\text { Control group } \\
(\mathrm{N}=4)\end{array}$ & $F$ \\
\hline Pre-test & $439.25(67.96)$ & $486.00(118.40)$ & $25.630^{\mathrm{b}, *}$ \\
Post-test & $325.50(37.40)$ & $335.50(163.55)$ & \\
$F$ & \multicolumn{3}{c}{$.156^{\mathrm{a}}$} \\
\hline
\end{tabular}

Values are presented as mean (SD).

aBetween subject effect, "'within subject effect, 'interaction effect. ${ }^{*} p<.05$. 
Table 3. Results from the pre-test and post-test comparison for the initiation ratio by parents' subgroup

\begin{tabular}{lccc}
\hline & $\begin{array}{c}\text { Experimental group } \\
(\mathrm{N}=4)\end{array}$ & $\begin{array}{c}\text { Control group } \\
(\mathrm{N}=4)\end{array}$ & $F$ \\
\hline Pre-test & $12.57(1.04)$ & $13.95(.74)$ & $1.071^{\mathrm{b}}$ \\
Post-test & $11.20(2.60)$ & $13.05(3.57)$ & \\
$F$ & \multicolumn{2}{c}{$1.791^{\mathrm{a}}$} & $.043^{\mathrm{c}}$ \\
\hline
\end{tabular}

Values are presented as mean (SD).

aBetween subject effect, ${ }^{b}$ within subject effect, ${ }^{\text {cinteraction effect. }}$

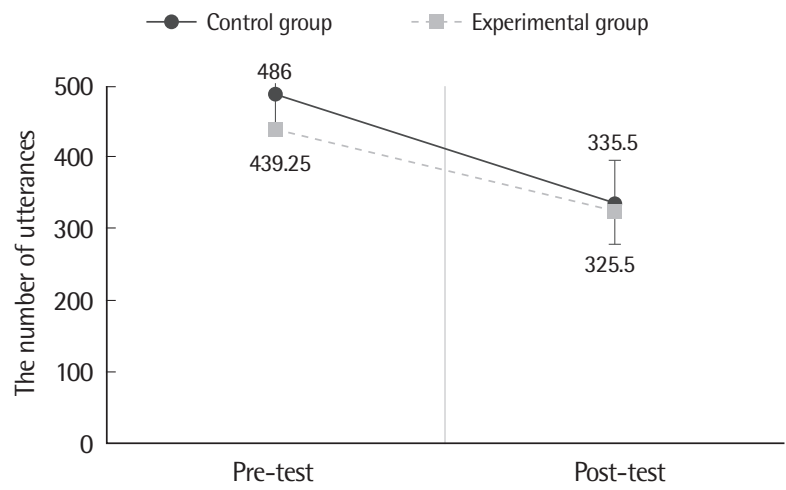

Figure 1. Results from the pre-test and post-test comparison for the number of utterances by parents' subgroup.

$1.791, p>.05)$, 평가 간 주효과 $\left(F_{(1,6)}=1.071, p>.05\right)$ 및 상호작용 검 정 결과가 유의하지 않은 것으로 나타났다 $\left(F_{(1,6)}=.043, p>.05\right)$. 실 험집단과 통제집단 부모 대화차례 개시 비율에 대한 기술통계량 및 통계 분석 결과는 Table 3에 제시되어 있다.

\section{중재에 따른 집단별 아동의 발화 수 및 대화차례 개시 비율 비교}

중재 이후 아동의 발화 수에 대한 집단 간 효과 검정 결과와 $\left(F_{(1,6)}\right.$ $=3.837, p>.05)$ 사전-사후 평가 간 주효과 $\left(F_{(1,6)}=1.790, p>.05\right)$ 는 유의하지 않았다. 사전.사후 평가와 발화분석 어플리케이션 사용 여부 간 상호작용 효과 또한 유의하지 않은 것으로 나타났다 $F_{(1,6)}$ $=.048, p>.05)$. 실험집단 및 통제집단 아동의 발화 수에 대한 기술 통계량 및 통계 분석 결과는 Table 4에 제시되어 있다.

중재 후 아동의 대화차례 개시 비율에 대한 사전과 사후 평가 간 주효과 $\left(F_{(1,6)}=2.822, p>.05\right)$, 집단 간 주효과 검정 결과는 유의하지 않았다 $\left(F_{(1,6)}=.273, p>.05\right)$. 하지만 사전·사후 평가와 어플리케이션 사용 여부 간 상호작용 효과는 유의한 것으로 나타났다 $\left(F_{(1,6)}=7.754\right.$, $p<.05)$. 집단별 아동의 대화차례 개시 비율에 대한 평가와 발화분 석 어플리케이션 사용 간 상호작용 효과가 유의함에 따라, 어플리 케이션을 사용한 아동 집단의 대화차례 개시 비율 증가 폭이 어플 리케이션을 사용하지 않은 집단의 대화차례 개시 비율 증가 폭에
Table 4. Results from the pre-test and post-test comparison for the number of utterances by children's subgroup

\begin{tabular}{lccc}
\hline & $\begin{array}{c}\text { Experimental group } \\
(\mathrm{N}=4)\end{array}$ & $\begin{array}{c}\text { Control group } \\
(\mathrm{N}=4)\end{array}$ & $F$ \\
\hline Pre-test & $160.50(50.23)$ & $76.75(72.20)$ & $1.790^{\mathrm{b}}$ \\
Post-test & $190.00(77.29)$ & $117.75(67.28)$ & \\
$F$ & \multicolumn{2}{c}{$3.837^{\mathrm{a}}$} & $.048^{\mathrm{c}}$ \\
\hline
\end{tabular}

Values are presented as mean (SD).

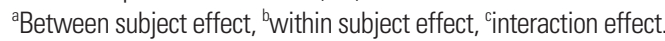

Table 5. Results from the pre-test and post-test comparison for the initiation ratio by children's subgroup

\begin{tabular}{lccc}
\hline & $\begin{array}{c}\text { Experimental group } \\
(\mathrm{N}=4)\end{array}$ & $\begin{array}{c}\text { Control group } \\
(\mathrm{N}=4)\end{array}$ & $F$ \\
\hline Pre-test & $8.70(1.97)$ & $14.85(4.73)$ & $2.822^{\mathrm{b}}$ \\
Post-test & $15.99(5.17)$ & $13.05(6.64)$ & \\
$F$ & \multicolumn{3}{c}{$.273^{\mathrm{a}}$} \\
\hline
\end{tabular}

Values are presented as mean (SD).

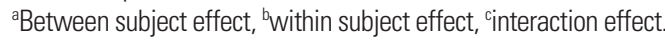
${ }^{*} p<.05$.

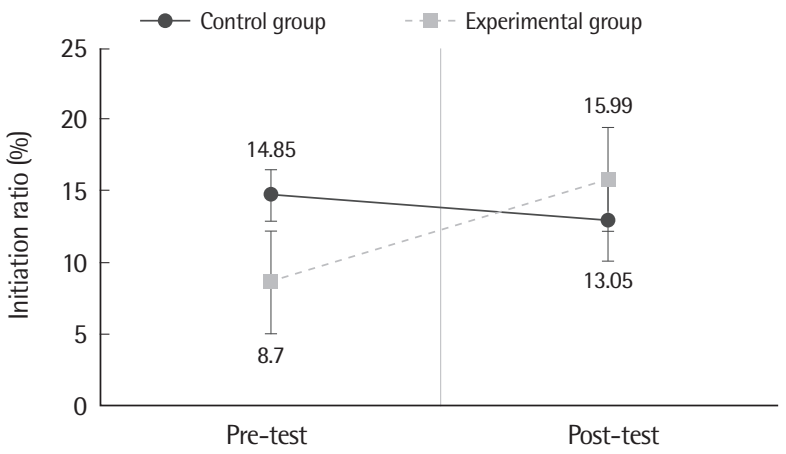

Figure 2. Results from the pre-test and post-test comparison for the initiation ratio by children's subgroup.

비해 유의하게 큰 것으로 나타났다. 실험집단과 통제집단 아동의 대화차례 개시 비율에 대한 기술통계량 및 통계 분석 결과는 Table 5, Figure 2에 제시되어 있다.

\section{논의 및 결론}

본 연구에서는 언어발달지연 아동의 부모를 대상으로 상호작용 촉진을 위한 부모교육을 실시하였다. 중재와 함께 실험집단에 부 모-아동 상호작용에 대한 피드백을 제공하는 발화분석 어플리케 이션을 제공하여 부모교육이 부모와 아동의 발화 수, 대화차례 개 시 비율에 영향을 주는지 알아보고자 하였다. 이에 따른 연구의 결 과는 다음과 같다. 
먼저, 실험집단 부모와 통제집단 부모 모두 부모교육 중재의 영 향으로 발화 수에서 유의미한 차이가 나타났다. 하지만 다른 종속 변수에서는 유의한 차이가 나타나지 않았다. 따라서 발화분석 어 플리케이션의 사용 여부는 실험집단 부모와 통제집단 부모의 부모 교육 중재 효과에 영향을 주지 않았다.

It Takes Two to Talk 부모교육 프로그램은 언어발달지연 부모의 지시적인 발화를 감소시키며 반응적인 발화는 증가시키는 것으로 나타났으며, 또한 더 느리고 덜 복잡한 언어를 구사하고 아동의 목 표 어휘를 더 잦은 빈도로 사용하는 데 도움을 줄 수 있다(Girolametto et al., 1996). 본 연구에서는 부모의 대화 차례 개시 비율 사 전·사후 평가 결과에서 유의미한 차이가 나타나지 않았으나, 부모 의 발화 수는 유의하게 감소하였다. 부모의 이러한 변화는 아동과 균형적인 상호작용의 중요성에 대한 부모교육 내용을 반영한 결과 로 보여진다. 부모-아동 상호작용에서 부모가 자신의 발화 수를 감 소시킴으로써 아이와 균형 있는 대화 차례를 갖는 경우 아이로 하 여금 상호작용을 주도하고 있다는 느낌을 받게 하며, 부모 발화 수 감소는 아동이 말할 수 있는 기회를 더 많이 주게 된다(Pepper \& Weitzman, 2004). 따라서 이러한 부모의 변화는 부모-아동 상호작 용 방식 전체에 긍정적 영향을 줄수 있다.

아동의 언어 환경과 언어 사용 양상을 분석하여 이에 대한 피드 백을 제공하는 기기인 LENA를 활용한 한 연구에서는 아동의 언어 환경 특히, 부모 발화의 중요성을 강조하고 LENA를 통한 분석 결 과를 매 시간 피드백 자료로서 제공하는 부모교육을 실시하였다. 이에 따라 부모가 산출하는 단어의 수(adult word count), 아동이 산출하는 발성의 수, 부모-아동 대화차례 횟수(conversational turn) 의 변화 양상에 대해 살펴보았다. 결과적으로 부모가 산출하는 단 어 수, 아동이 산출하는 발성 수, 대화 차례 모두 부모교육 중재와 기기사용을 통하여 증가한 것으로 나타났다(Rafdal, 2011). 이와 달 리 본 연구에서 부모의 발화 수는 부모교육 이후 유의하게 감소한 것으로 나타났다. 이는 두 연구에서 실시된 부모교육 내용에서 부 모 발화의 역할에 대한 관점을 달리하였기 때문인 것으로 분석된 다. 기존 연구에서는 부모 발화의 양적 증가가 아동에게 더 많은 언 어적 자극을 제공한다는 관점에 의해 중재가 이루어졌다면, 본 연 구에서는 부모와 아동이 균형적인 말차례를 유지하면서 아동이 상 호작용을 주도할 수 있도록 부모의 전체적인 발화 수를 줄이고 아 이와 균형적인 상호작용을 할 수 있도록 독려하였던 점을 반영하여 기존과상반된 연구 결과가 나타난 것으로 볼 수 있다.

아동의 발화 수, 대화차례 개시 비율이 발화분석 어플리케이션 을 사용한 실험집단과 그렇지 않은 통제집단에서 다른 양상을 나 타내는지 알아보았다. 부모교육 이후 두 집단에서는 부모교육 중재
로 인한 주효과 혹은 어플리케이션 사용에 따른 주효과가 나타나 지 않았다. 하지만 아동의 대화차례 개시 비율에서 어플리케이션 사용과 부모교육 중재로 인한 상호작용 효과가 유의하게 나타났 다. 즉, 어플리케이션을 사용한 집단 아동의 중재 효과가 그렇지 않 은 아동 집단에 비해 더 크게 나타났으며 이는 아동의 상호작용 방 식을 통제집단에 비해 더 주도적으로 만드는 것에 기여하였다.

중재 이후 발화분석 어플리케이션 사용의 효과성에 대한 부모 응답지에서, 실험집단 부모들은 어플리케이션이 제공하는 실시간 피드백이 상호작용 동안 부모 자신의 발화 혹은 개시의 양이 상당 히 많다는 것을 인지시키며, 아동과의 균형된 상호작용의 필요성을 상기시킨다고 답변하였다. 이러한 주요 응답으로 미루어 보아 아동 의 상호작용 양상에 대한 어플리케이션의 피드백은 부모로 하여금 아동 상호작용의 특성에 대해 인지시키고 이에 대한 전략을 세울 수 있도록 함으로써 아동의 변화를 이끌어낼 수 있었던 것으로 분 석된다.

아동이 부모와의 상호작용을 주도적으로 이끌어가는 경우 더 많은 언어적.비언어적 표현을 필요로 하게 되며 이 가운데서 더 많 은 언어를 학습할 수 있다. 때문에 언어발달지연 아동이 주도적인 상호작용 방식을 가지는 것은 언어발달 촉진을 위해 필요한 과정이 다(Pepper \& Weitzman, 2004). 본 연구에서 발화분석 어플리케이 션을 사용한 집단의 아동은 통제집단 아동에 비해 더 큰 폭으로 대 화차례 개시 비율이 상승하였다. 이는 곧 부모에게 제공되는 어플 리케이션의 피드백이 아동의 상호작용 방식을 보다 주도적으로 변 화시켜 아동의 언어발달 촉진에 긍정적인 영향을 줄 수 있음을 시 사한다. 단지, 부모 집단의 변화가 두드러지지 않았음에도 불구하 고 실험집단 아동에게서 상호작용 상의 변화가 나타난 것은, 어플 리케이션 사용이 부모가 아동의 주도적인 상호작용을 유도할 수 있는 비언어적 전략사용을 도왔기 때문인 것으로 분석된다. It Takes Two to Talk에서는 아동이 상호작용을 주도하게 하기 위해 얼굴을 마주보기, 대화차례를 개시하도록 충분한 시간 제공하기 등 다양 한 비언어적 전략을 교수한다(Pepper \& Weitzman, 2004). 발화분 석 어플리케이션은 이러한 전략을 부모가 가정에서 적용했을 때에 아동의 상호작용에 나타나는 변화를 즉각적 피드백 및 누적된 결 과치를 통해 제시함으로써 부모의 전략 사용에 대한 효과를 시각 적으로 보여줄 수 있다. 또한 이러한 부모의 변화가 아동의 상호작 용에 긍정적 영향을 주어 아동이 보다 주도적인 상호작용을 할 수 있도록 도움을 준 것으로 분석된다.

스마트 기기를 활용한 중재는 이전에도 다수 이루어져왔다. 그 중 LENA를 활용한 연구에서는 아동의 주 양육자에게 단 1 회기의 부모교육 이후 가정에서 기기를 활용한 중재를 주 1 회씩 총 6 주에 
,

걸쳐 실시한 결과, 부모의 발화량과 대화차례 주고받기 횟수가 유 의하게 증가했다(Suskind et al., 2013). 이처럼 기기를 활용하여 이 루어진 기존의 연구에서는 주로 아동의 주요한 언어 환경인 주 양 육자의 언어 사용 변화에 초점을 두어 주 양육자의 발화량 증가를 이끌어내는, 기기를 통한 아동 언어의 간접적 중재 효과를 검증하 는 것에 그쳤다. 그러나 본 연구는 더 나아가 기기 사용 및 부모교육 을 통한 아동 상호작용 방식의 변화를 목표로 하여 부모 및 아동에 직접 적용함으로써 아동 집단에서 그 효과를 확인하였다. 또한 기 기를 활용한 다수의 연구들이 주로 장애 유형에 따른 아동의 언어 적 특성 및 언어 환경 분석에 초점을 맞추어왔다면(Ambrose, VanDam, \& Moeller, 2014; Burgess, Audet, \& Harjusola-Webb, 2013), 본 연구는 언어발달지연 아동의 중재 효율성을 높이기 위한 방법 으로 기기적 접근을 실시하여 임상에의 적용 가능성을 확인했다 는 점에서 큰 의의가 있다.

본 연구의 제한점 및 제언 사항은 다음과 같다. 먼저, 본 연구의 대상자는 부모-아동 8쌍, 실험.통제집단 각 4쌍으로 대상자가 수가 적기 때문에 연구에서 도출된 결과를 모든 집단에 일반화하기에 어려움이 따를 수 있다. 후속 연구에서는 대상자 수를 더 늘려 부모 교육과 어플리케이션의 효과성에 대해 더 정확한 검증이 이루어져 야 할 것이다. 또한, 이번 연구를 통해서는 부모교육의 효과와 발화 분석 어플리케이션 사용 효과를 완전히 분리해서 볼 수 없으므로 후속 연구에서는 발화분석 어플리케이션만을 사용한 중재를 실시 함으로써 어플리케이션 활용 가능성에 대해 심도 있는 연구가 이 루어져야 한다. 더불어, 만 2-3세 언어발달지연 아동의 상호작용 과 정에서 아동의 발화 수, 대화차례 개시뿐 아니라 대화차례 주고받 기 및 대화차례 유지에 관한 중요성이 부각되고 있으므로 이에 대 한 추가적 연구도 필요할 것이다. 마지막으로, 본 연구에서 사용된 발화분석 어플리케이션에 대한 기술적 보완을 실시하여 분석 정확 도를 더욱 높임으로써 발화분석 어플리케이션을 통하여 산출된 결과를 직접 연구에 활용하여 그 가능성을 검증하는 연구가 추가 적으로 이루어져야 할 것이다.

\section{REFERENCES}

Ambrose, S. E., VanDam, M., \& Moeller, M. P. (2014). Linguistic input, electronic media, and communication outcomes of toddlers with hearing loss. Ear and Hearing, 35, 139-147.

Brown, R. (1973). A first language: the early stages. Cambridge, MA: Harvard University Press.

Burgess, S., Audet, L., \& Harjusola-Webb, S. (2013). Quantitative and qualita- tive characteristics of the school and home language environments of preschool-aged children with ASD. Journal of Communication Disorders, 46, 428-439.

Cho, M. R., \& Lee, Y. (2010). Communicative behaviors of toddlers with or without language delay. Korean Journal of Early Childhood Special Education, 10, 31-46.

Cunningham, C. E., Siegel, L. S., Van der Spuy, H. I. J., Clark, M. L., \& Bow, S. J. (1985). The behavioral and linguistic interactions of specifically languagedelayed and normal boys with their mothers. Child Development, 56, 13891403.

Fischel, J. E., Whitehurst, G. J., Caulfield, M. B., \& DeBaryshe, B. (1989). Language growth in children with expressive language delay. Pediatrics, 83, 218-227.

Girolametto, L., Pearce, P. S., \& Weitzman, E. (1996). Interactive focused stimulation for toddlers with expressive vocabulary delays. Journal of Speech, Language, and Hearing Research, 39, 1274-1283.

Girolametto, L., Weitzman, E., \& Clements-Baartman, J. (1998). Vocabulary intervention for children with Down syndrome: parent training using focused stimulation. Infant-Toddler Intervention, 8, 109-125.

Goffman, L., \& Leonard, J. (2000). Growth of language skills in preschool children with specific language impairment: implications for assessment and intervention. American Journal of Speech-Language Pathology, 9, 151161.

Hegde, M. N. (1995). Introduction to communicative disorders. Austin, TX: Pro-Ed.

Hwang, I., Yoo, C., Hwang, C., Yim, D., Lee, Y., Min, C., ... \& Song, J. (2014). TalkBetter: family-driven mobile intervention care for children with language delay. In Proceedings of the 17th ACM Conference on Computer Supported Cooperative Work \& Social Computing, Baltimore, MD, 1283-1296.

Jung, P. Y., Sim, H. S., \& Yim, D. (2012). Effects of parent training program on communicative abilities of the young children with cerebral palsy and their mother. Korean Journal of Special Education, 47, 39-62.

Kim, J. M., \& Lee, S. H. (2007). The effect of "It Takes Two to Tall" program on communicative abilities of the children with developmental language delay and their parents' behaviors. Korean Journal of Communication Disorders, 12, 607-624.

Kim, Y. T. (1997). Foundation of length of utterance in 2 to 4 year-old children. Korean Journal of Communication Disorders, 2, 5-26.

Klee, T. (1992). Developmental and diagnostic characteristics of quantitative measures of children's language production. Topics in Language Disorders, 
$12,28-41$.

Kuhl, P. K., Conboy, B. T., Padden, D., Nelson, T., \& Pruitt, J. (2005). Early speech perception and later language development: implications for the “Critical Period”. Language Learning and Development, 1, 237-264.

Lee, H. J., \& Kim, Y. T. (1999). Measures of utterance length of normal and language-delayed children. Korean Journal of Communication Disorders, 4 , 153-166.

Lee, H. J., \& Kim, Y. T. (2001). Turn-taking characteristics of Specific language impairment and normal children. Korean Journal of Communication Disorders, 6, 293-312.

Lee, Y., \& Lee, H. J. (2013). Conversational turn-taking of toddlers with language delay. Special Education Research, 12, 357-377.

Owens, R. E. (1996). Language development: an introduction. Boston, MA: Allyn \& Bacon.

Owens, R. E. (2004). Language disorders: a functional approach to assessment and intervention (4th ed.). Boston, MA: Allyn \& Bacon.

Pae, S., \& Kwak, K. C. (2011). Korean MacArthur-Bates Communicative Development Inventories (KM-B CDI). Seoul: Mindpress.

Paul, R. (1991). Profiles of toddlers with slow expressive language development. Topics in Language Disorders, 11, 1-13.

Paul, R., \& Shiffer, M. E. (1991). Communicative initiations in normal and late-talking toddlers. Applied Psycholinguistics, 12, 419-431.

Paul, R., Hernandez, R., Taylor, L., \& Johnson, K. (1996). Narrative development in late talkers: early school age. Journal of Speech, Language, and Hearing Research, 39, 1295-1303.

Pennington, L. (2009). Effects of it takes two to talk: the Hanen program for parents of preschool children with cerebral palsy: findings from an exploratory study. Journal of Speech, Language, and Hearing Research, 52, 11211138.

Pepper, J., \& Weitzman, E. (2004). It takes two to talk: a practical guide for parents of children with language delays (3rd ed.). Toronto: The Hanen Centre.
Rafdal, B. H. (2011). Effects of graphical feedback and coaching on the quantity and quality of parent-child language interaction (Doctoral dissertation). University of Minnesota, Minneapolis, MN.

Rescorla, L. (2005). Age 13 language and reading outcomes in late-talking toddlers. Journal of Speech, Language, and Hearing Research, 48, 459-472.

Rescorla, L. (2009). Age 17 language and reading outcomes in late-talking toddlers: support for a dimensional perspective on language delay. Journal of Speech, Language, and Hearing Research, 52, 16-30.

Rescorla, L., Roberts, J., \& Dahlsgaard, K. (1997). Late talkers at 2: outcome at age 3. Journal of Speech, Language, and Hearing Research, 40, 556-566.

Rice, M. L., Taylor, C. L., \& Zubrick, S. R. (2008). Language outcomes of 7-yearold children with or without a history of late language emergence at 24 months. Journal of Speech, Language, and Hearing Research, 51, 394-407.

Scarborough, H. S., \& Dobrich, W. (1990). Development of children with early language delay. Journal of Speech, Language, and Hearing Research, $33,70-83$.

Suskind, D., Leffel, K. R., Hernandez, M. W., Sapolich, S. G., Suskind, E., Kirkham, E., ... \& Meehan, P. (2013). An exploratory study of "Quantitative Linguistic Feedback": effect of LENA feedback on adult language production. Communication Disorders Quarterly, 34, 199-209.

Tsybina, I., \& Eriks-Brophy, A. (2007). Issues in research on children with early language delay. Contemporary Issues in Communication Science and Disorders, 34, 118-133.

Whitehurst, G. J., \& Fischel, J. E. (1994). Practitioner review: early developmental language delay: what, if anything, should the clinician do about it? Journal of Child Psychology and Psychiatry, 35, 613-648.

Yim, D., Park, W., Cheon, S., Lee, Y. J., \& Lee, J. (2015). Interaction skills via spontaneous speech sample analysis: 2- to 5-year-old children with and without language impairment. Communication Sciences \& Disorders, 20, 364-373. 
Wonjeong Park, et al. • The Effect of Parental Education Using Smartphone Application

Appendix 1. Topics of the parental education

\begin{tabular}{|c|c|c|c|}
\hline 회기 & 주제 & 방법 & 내용 \\
\hline \multirow[t]{6}{*}{1} & 아이가 주도하게 하기 & 의사소통과 상호작용 이해하기 & - 아동의 상호작용 단계 \\
\hline & & & - 아동의 상호작용 유형 \\
\hline & & & - 부모의 상호작용 유형 \\
\hline & & 아이가 주도하게 하기 전략 & - 아동의 몸짓, 행동, 표정 관찰 \\
\hline & & & - 아이가 반응할 수 있는 시간 주기 \\
\hline & & & - 말이나 소리에 즉시 관심 기울이기 \\
\hline \multirow[t]{6}{*}{2} & 아이의 주도 따르기 & 아이의 주도를 따르기 전략 & - 아이에게 메시지를 받았음을 알려주기 \\
\hline & & & · 아이의 놀이에 참여 \\
\hline & & & - 아이의 행동·표정·소리·말 등을 모방 \\
\hline & & & - 아이의 반응을 해석 \\
\hline & & & - 아이의 말이나 행동에 코멘트 \\
\hline & & 의사소통 단계에 따른 전략 & - 각 의사소통 단계에 적합한 전략 사용 방식 \\
\hline 3 & \multicolumn{3}{|c|}{ 비디오 피드백 회기 } \\
\hline \multirow[t]{2}{*}{4} & 대화 주고받기 & 아이에게 질문하기 & - 예/아니오, 선택형, Wh- 질문 통해 대화 지속하기 \\
\hline & & 대화 주고받기 위한 신호주기 & - 대화를 주고받을 차례라는 신호를 표정, 몸짓 또는 기다리기를 통해 알려주기 \\
\hline \multirow[t]{6}{*}{5} & 상호작용에 언어 덧붙이기 & 언어 덧붙이기 & - 다양한 낱말 사용하기 \\
\hline & & & - 아이의 메시지 확장 \\
\hline & & 언어 강조하기 & - 짧고 간단하게 말하기 \\
\hline & & & - 중요한 낱말 강조하기 \\
\hline & & & · 제스처로 보여주기 \\
\hline & & & · 천천히 말하기 \\
\hline \multirow[t]{4}{*}{6} & 일상에서 언어촉진하기 & 아동과 함께 책 읽기 & - 책 읽으며 의사소통 하기 \\
\hline & & & - 책 읽으며 언어 확장하기 \\
\hline & & 노래로 상호작용하기 & - 노래를 통한 활동에서 의사소통 기술 사용하기 \\
\hline & & & - 노래 부르며 낱말 학습하기 \\
\hline
\end{tabular}

Appendix 2. Definitions for each part of spontaneous sample analysis

\begin{tabular}{ll}
\hline 평가 항목 & \multicolumn{1}{c}{ 정의 및 규준 } \\
\hline 발화 수 & Lee와 $\operatorname{Kim}(2001)$ 에서 제시된 ‘말차례에서의 발화 구분 원칙’을 기초로 하여 발화를 구분하였다. 따라서 한 문장을 한 발화로 \\
& 보았으며, 약 5초 가량의 시간이 경과하거나 두드러진 운율의 변화, 주제의 변화가 있을 때 발화의 수를 나누었다. \\
대화차례 개시 횟수 & Lee와 Lee (2013)에서 언급된 대화차례 개시의 정의에 따라 대화차례 개시를 (1) 아동이 새로운 주제로 처음 대화를 시작하는 경우, \\
& 혹은 (2) 3초 이상의 대화 중단이 발생한 이후에 아동이 먼저 대화차례를 시작하는 경우로 보았다.
\end{tabular}




\section{국문초록}

\section{발화분석 어플리케이션을 활용한 상호작용 증진 부모교육이 언어발달지연 아동과 부모의 발화 및 대화차례 개시에 미치는 영향}

박원정 - 임동선

이화여자대학교 언어병리학과

배경 및 목적: 언어발달지연 아동의 조기중재 방법으로서 실시되는 부모교육은 조기중재에 효과적이나 부모가 학습한 전략을 가정에 서 적용하고 이를 일반화시키는 것에 어려움이 따른다. 따라서 본 연구는 부모교육의 효과를 높여줄 수 있는 도구로서 발화분석 어플 리케이션의 활용가능성에 대해 알아보는 것을 목적으로 하였다. 방법: 만 2-3세 언어발달지연 아동과 그 부모, 총 8쌍이 연구에 참여하 였다. 자발화 수집을 통한 사전 평가 실시 이후, 총 6 주간의 부모교육이 실시되었다. 부모교육이 실시되는 동안 4 쌍의 실험집단 부모는 아동과의 상호작용에 발화분석 어플리케이션을 사용하였으며, 나머지 4 쌍의 부모는 상호작용에 관한 일지만을 적었다. 사후평가 또한 사전평가와마찬가지로 놀이 상황에서의 자발화 수집을 통해 이루어졌으며, 사전 및 사후평가에서 수집된 자료는 발화 수, 대화차례 개 시 비율로 분석되었다. 결과: 부모교육 이후 부모의 발화 수가 유의하게 줄어들었으며, 발화분석 어플리케이션을 사용한 아동 집단은 통제집단에 비해 대화차례 개시 비율 변화 폭이 더 큰 것으로 나타났다. 논의 및 결론: 부모교육은 부모-아동 상호작용에 긍정적 효과 가 있으며, 발화 분석 어플리케이션이 이러한 중재 효과를 높이는 것에 도움을 주는 것으로 나타났다.

핵심어: 언어발달지연, 부모교육, 발화분석 어플리케이션, 대화차례 개시 비율, 발화 수

본 연구는 2013년도 정부(미래창조과학부)의 재원으로 한국연구재단의 지원을 받아 연구되었음(NRF-2013R1A2A2A03068010).

\section{참고문헌}

김영태(1997). 한국 2-4세 아동의 발화길이에 관한 기초연구. 말-언어장애연구, 2, 5-26.

김정미, 이수향(2007). It Takes Two To Talk 부모교육 프로그램이 언어발달지체 아동의 의사소통과 부모의 행동에 미치는 효과. 언어청각장애연구,

12, 607-624.

배소영, 곽금주(2011). 한국판 맥아더-베이츠 의사소통 발달평가(K MB CDI). 서울: 마인드프레스.

이윤경, 이효주(2013). 표현언어발달지체 영유아의 대화차례 주고받기 특성. 특수교육, 12,357-377.

이효진, 김영태(2001). 단순언어장애 아동의 대화 말차례 특성. 언어청각장애연구, 6, 293-312.

이희정, 김영태(1999). 자발화 표본 분석의 정량화를 통한 언어발달지체의 판별 연구: 발화길이를 중심으로. 언어청각장애연구, 4, 153-166.

임동선, 박원정, 천성혜, 이여진, 이지연(2015). 자발화 분석을 통한 만 2-5세 아동의 상호작용 기술 특성 및 언어발달지체 아동 비교 연구. 언어청각장

애연구, 20, 364-373.

정필연, 심현섭, 임동선(2012). 상호작용촉진 부모교육프로그램이 취학전 뇌성마비아동의 말명료도 및 어머니와의 상호작용에 미치는 영향. 특수교

육학연구, 47, 39-62.

조미라, 이윤경(2010). 언어발달지체 유아와 일반 유아의 의사소통 행동 비교. 유아특수교육연구, 10, 31-46. 